\title{
Correction to: Stakeholder Perceptions of the Ecosystem Services and Human Well-Being Impacts of Palm Oil Biofuels in Indonesia and Malaysia
}

Raquel Moreno-Peñaranda, Alexandros Gasparatos, Per Stromberg, Aki Suwa, and Jose A. Puppim de Oliveira

Correction to:

Chapter 10 in: K. Takeuchi et al. (eds.), Biofuels and Sustainability, Science for Sustainable Societies, https://doi.org/10.1007/978-4-431-54895-9_10

The chapter was originally published with an incorrect citation and its reference. The occurrence of reference and its citation has been removed from page numbers 170 (line $26 \& 27$ ) and 146 (line 14). 